\title{
The Utilization of Quality Control Chart to Examine the Chemical Properties and Bacterial Water in Al-Dlail Area in the Zarqa Governorate
}

\author{
Adeeb Ahmed Ali AL Rahamneh ${ }^{1}$ \\ ${ }^{1}$ Assosiate Professor, Applied Statistics, Faculty of Business, AL Balqa Applied University, Jordan \\ Correspondence: Adeeb Ahmed Ali AL Rahamneh, Applied Statistics, Faculty of Business, AL Balqa Applied \\ University, Jordan. E-mail: moheeb982005@yahoo.co.uk
}

Received: May 15, 2017

Accepted: June 3, 2017

Online Published: June 14, 2017

doi:10.5539/mas.v11n7p74

URL: https://doi.org/10.5539/mas.v11n7p74

\begin{abstract}
This study focuses on the amount of chemical properties and microbiology (T.D.S ,T.H,MPN) into the water provided by the environmental health from the private wells Al-Dlail laboratories in a Zarqa Governorate. The research problem focuses on the chemical properties and microbiology (T.D.S, T.H, MPN) of the amount of the water provided by the environmental health of the private wells of Al-Dlail laboratories in a Zarqa Governorate. The research object was to develop the necessary treatments for reducing the presence of unauthorized descent from T.D.S, T.H and MPN.

The analytical research methodology was adopted for the case study analysis to achieve the purpose of this research which was to develop necessary treatments to reduce the presence of unauthorized descent from T.D.S, T.H and MPN. To achieve the study objectives, the study uses (Minitab). Based on the statistical analysis, the main results are:

The Control Limits for the Total Dissolved Solid (T.D.S) and the Total Hardness (T.H) are within acceptable limits In the Control Limits for the Most Probable Number (MPN), some readings are beyond the extent of control. Also, there are two samples $(15,16)$ that breach the specification and the bacterium Bacillus colon(MPN) limits, which means exceeding the allowed percentage of the limit.

The researcher concluded that the Control Limits for the Total Dissolved Solid (T.D.S) are within acceptable limits and the Control Limits for the Total Hardness (T.H) are within acceptable limits. The researcher recommends that the international standard must be adopted in water treatment.
\end{abstract}

Keywords: Jordan, Most Probable Number (MPN),Total Dissolved Solid(T.D.S), Total Hardness (T.H), Zarqa

\section{Introduction}

The water quality is a key factor for the survival of human beings, basically for global developments of economics and technology. The quality level of water is one of the competitive priorities, which aims to encourage mangers to achieve their organizations' goals particularly those who are in charge of water supply (Patil et al, 2012).

The subject of quality of goods and services has occupied the priority attention in order to improve productivity after it turned out to be the main factor in the success of organizations. A tool used in quality maps of the quality control charts are an essential means to adjust operations statistically (Statistical Process Control). Using surveillance maps can follow up the progress of operations and the use of statistics to observe if there was abnormal change in the process. It enables to conduct early intervention to correct the process and help to determine the cause of change (Jarugulla \& Krishna, 2017).

Water is the basis of life on Earth, the main component of the globe and covers seventy-one percent of the earth. Water has three states: solid, liquid or gas. Water in its natural state has three main characteristics: it is colorless, tasteless and odorless. Like other elements, water is considered to be an essential chemical compound. It consists of two atoms of hydrogen and one oxygen atom (Taruna \& Chaudhary, 2013).

The study highlights the drinking water, which must be characterized by certain qualities in order to be safe to drink. It is known information that the human body consists of high percentage of water up to more than 
seventy-five percent. Thus the human being needs to drink a sufficient amount of water during the day to compensate any shortage that may lead to dehydration or cause certain diseases in particular to those who do not have the minimum recommended amount of water. Therefore, the amount of water lost daily must be replaced by equivalent amount of daily water intake to maintain a proper balance. The water that human intakes must be clean and pure with good health specifications. Consequently, the water must be checked before it is distributed as water undrinkable.

Ahmed and Bajahlan (2009) paid attention towards drinking bottled water quality with respect to different aspects such as chemical, biological and etc. in the Saudi Aribia. They found that the quality of drinking bottled water compared with tap water showed that there were no significant differences between them.

Semerjian (2011) investigated the levels of physicochemical of water then compared the results with Lebanese institution standards for bottled water.

Abdulraheem, et al., (2012) measured and compared bacterial concentration of endotoxin in a variety of samples of tap and bottled water in Kuwait by using the Limulus Amoebocyte lysate test. They found that the drinking bottled water has less endotoxin compared to the tap water.

In Jordan, there are many problems in the induction of the data related to the chemical properties and bacterial water samples (Water Authority of Jordan Laboratories and Quality Sector Water Analysis,2013). Al-Kharabsheh and Alatoum (2013) examined 24 samples of water for their physical, chemical and biological characteristics. They found that four types of water were observed in the spring water; alkaline earth water with bicarbonate and chloride, alkaline earth water with increased portion of alkalies with prevailing bicarbonate, alkaline earth water with increased portion of alkalies with prevailing chloride and alkaline water with prevailing chloride. The chemistry of the water is originated from the dissolution of carbonate rocks and evaporated deposits such as Gypsum resulted from irrigation water.

This research is based on the readings of special Environmental Health of the private wells of the Al-Dlail laboratories in a Zarqa Governorate. It was conducted through the use of quality control and the Adoption of data measurements, Total Dissolved Solid (T.D.S), Total Hardness (T.H) and MPN/100mm for the period of 8 / 6 / 2015 to 30 / 9 / 2015.

\section{The Importance of the Research}

The control charts statistical data from the means of decision-making where it contributes to determine the lower, central, and upper levels of the bacterial examination of water and determines the readings beyond the permissible limits for the purpose of processing.

\section{The Problem of the Research}

The water samples which were tested showed that chemical and physical materials have a negative impact on human health. While, this research focuses on the chemical properties and microbiology (T.D.S ,T.H,MPN) of the amount of the water provided by the environmental health of the private wells of Al-Dlail laboratories in a Zarqa Governorate, which expected to have an impact on human health.

\section{The Objective of Research}

The research aims to identify glitches caused by the presence of unauthorized descent from T.D.S, T.H, MPN in the amount of the water provided by the environmental health of the private wells of Al-Dlail laboratories in a Zarqa Governorate. In other words, the purpose of this research is to study the necessary treatments required to reduce the presence of unauthorized descent from T.D.S, T.H and MPN.

\section{Assumptions of the Research}

There are three assumptions:

1. The TDS recorded readings of environmental health laboratories of the private wells of Al-DLail in a Zarqa Governorate is higher than the upper control limits.

2. The TH recorded readings of environmental health laboratories of the private wells of Al-DLail in a Zarqa Governorate is lower than the lower control limits.

3. The ratios MPN recorded readings from the laboratories of Environmental Health of the private wells of Al-DLail in a Zarqa Governorate is higher than the upper control limits.

\section{Level of the Research}

1. The tests of rates TDS, TH, MPN, is conducted by using samples of water from the environmental health 
laboratories of private wells of Al-Dlail in a Zarqa Governorate for the period from 06/08/2015 -to- 30/9/1015.

2. The results of the samples taken from the laboratories of environmental health of the ministry of health and the water samples from the private wells in Al-Dlail of Zarqa Governorate, from 8 / 6 / 2015 to 30 / 9 / 2015, as these tests are conducted once a year. The samples were taken in 2015 because the results of 2016 have not been adopted yet.

\section{The Concept of Control Chart}

The concept of control chart is a graph used to study how process changes over time. Data are plotted in time ordered. A control chart always has a central line for the average, an upper line for the upper control limit and a lower line for the lower control limit. These lines are determined from historical data. By comparing current data to these lines, it is expected to draw conclusions about whether the variation of process is being consistent (in control) or is unpredictable (out of control, affected by special causes of variation) ( Nancy,2005).

\subsection{When to Use a Control Chart}

1. Controlling ongoing processes by finding and correcting problems as they occur.

2. Predicting the expected range of outcomes from a process.

3. Determining whether a process is stable (in statistical control).

4. Analyzing patterns of process variation from special causes (non-routine events) or common causes (built into the process).

5. Determining whether the quality improvement project should aim to prevent specific problems or to make fundamental changes to the process ( Nancy,2005).

\subsection{The Basic Components of control charts}

1. There are three components:

2. Upper control limit

3. Central limit

4. Lower control limit ( Nancy,2005).

\subsection{Variables Control Chart Types}

Variables control chart types consist of the following:

\subsubsection{X-bar Chart}

when constructing $\mathrm{X}$-bar chart for a specific procedure $(\mathrm{K})$ will be drawn from the sample where:

Every sample $(\mathrm{N})$ is a unit and requires to be differentiated in three situations:

In the case of the Mean of the Population $(\mu)$ and standard deviation $(\sigma)$ of the population here are three limits of the control chart are calculated as follows: (Osama,2008)

$$
\begin{gathered}
U C L=\mu+\left(\frac{3 \sigma}{\sqrt{n}}\right) \\
C L=\mu \\
L C L=\mu-\left(\frac{3 \sigma}{\sqrt{n}}\right)
\end{gathered}
$$

In the case of population, Mean $(\mu)$ is unknown but the standard deviation $(\sigma)$ is known we substitute $(\mu)$ with

( $\overline{\bar{X}}$ )and the three limits for the control chart as follows: (Osama,2008)

$$
\begin{aligned}
U C L & =\overline{\bar{X}}+\left(\frac{3 \sigma}{\sqrt{n}}\right) \\
C L & =\overline{\bar{X}}
\end{aligned}
$$




$$
L C L=\overline{\bar{X}}-\left(\frac{3 \sigma}{\sqrt{n}}\right)
$$

Where $(\overline{\bar{X}})$ general Mean

In the case of the standard deviation for the population $(\sigma)$ is unknown. Minitab program provides three substitutes to calculate or estimate the Standard deviation for a population.

\subsubsection{R-bar Chart}

The three limits are calculated for the control chart as follows: (Osama,2008)

$$
\begin{gathered}
U C L=\mu+\left(A_{2} \bar{R}\right) \\
C L=\mu \\
L C L=\mu-\left(A_{2} \bar{R}\right)
\end{gathered}
$$

Where: $(\bar{R})$ : Represents (Median Average $)=\{$ first sample range + second sample range $+\ldots \ldots+(\mathrm{K})$ sample range\} / number of samples (K)

$A_{2}$ : The amount that is extracted from a table in the control chart.

\subsubsection{S - bar}

The three limits are calculated for the control chart as follows: ( Nancy,2005).

$$
\begin{array}{r}
U C L=\mu+\left(\frac{3 S}{\sqrt{n}}\right) \\
C L=\mu \\
L C L=\mu-\left(\frac{3 S}{\sqrt{n}}\right)
\end{array}
$$

Where $(\vec{S})$ : Average standard deviations for the samples $=\{$ Standard deviations for sample $1+$ standard deviations for sample $2+$ + Standard deviations for sample $(\mathrm{K})\}$ / number of sample (K) 7.3.4 Pooled Standard Deviation

The three limits are calculated for the control chart as follows: (Nancy,2005).

$$
\begin{gathered}
U C L=\mu+\left(\frac{3(S) \text { Pooled }}{\sqrt{n}}\right) \\
C L=\mu \\
L C L=\mu-\left(\frac{3(S) \text { Pooled }}{\sqrt{n}}\right)
\end{gathered}
$$

Where: (S) Pooled = standard deviation for the sample.

However, if the mean population $(\mu)$ is unknown (in the last three substitutes), we will substitute it with population mean $(\overline{\bar{X}})$ 


\subsubsection{S-Chart}

All samples standard deviations (S- Charts) are examined in this type of quality control charts, to identify the existence of an abnormal sample that comes out of the expected range of the deviations limits in the production process, Osama (2008), recommended while using the $S$ chart for the number of samples to be greater than or equal to (9). If the sample was less than 9, another type of charts can be used, which is the Range Chart ( $\mathrm{R}$ Chart).

When constructing the S - Chart, we should differentiate these two cases:

1. If the standard deviation of the population $(\sigma)$ is known.

2. If the standard deviation of the population is unknown.

If the standard deviation of the population $(\sigma)$ is known, the limits of the S-Chart are calculated as follows: (Osama,2008)

$$
\begin{gathered}
U C L=B_{6} \cdot \sigma \\
C L=C_{4} \cdot \sigma \\
L C L=B_{5} . \sigma
\end{gathered}
$$

Knowing that: $B_{5}, B_{6}, C_{4}$ and are fixed values which are extracted from the control chart table

If the standard deviation of the population is unknown, we can construct the S-Chart in two ways:

Option 1: Use standard deviation for sample (S-bar):

In this case we can use the calculation of the control chart limits as follows: (Osama, 2008)

$$
\begin{gathered}
U C L=B_{6} \frac{S}{C_{4}} \\
C L=S \\
L C L=B_{5} \frac{S}{C_{4}}
\end{gathered}
$$

Where: (s): standard deviation mean of the samples

Option 2: Using the pooled standard deviation.

In this case we can use the calculation of the control chart limits as follows: (Osama, 2008)

$$
\begin{gathered}
U C L=B_{6} \frac{\text { Spooled }}{C_{4}} \\
C L=\text { SPooled } \\
U C L=B_{6} \frac{\text { Spooled }}{C_{4}}
\end{gathered}
$$

The samples are not required to be equal.

Where (S) Pooled: The pooled standard deviations calculated with the same rule as control chart (Mean Control chart) 
The pooled standard deviations calculated with the same rule as control chart (Mean Control chart)

$$
S(\text { Pooled })=\sqrt{\frac{(n-1)\left(S_{1}^{2}+S_{2}^{2}+. . S_{K}^{2}\right)}{K(n-1)}}
$$

\section{Where:}

$S_{1}^{2}:$ is the variance of the first sample.

$S_{2}{ }^{2}$ : is the variance of the second sample.

$S_{K}{ }^{2}:$ is the variance of the $\mathrm{k}$ sample.

Importance of control charts

1) To identify flaws product or service.

2) To indicate that the product or service processes deviated from the required specifications.

3) To adjust processes statistically. SPC helps to take appropriate decisions.

4) To provide knowledge of the senior management on the enhancements and changes of the operations.

\section{Literature Review}

Many previous studies handled some physical, Microbial, and chemical properties of drinking water, those previous studies aimed to explore of the laboratory results that explained the water treatment, for example: Shekha, et al (2013), conducted a study which aimed to investigate and assess physical, chemical and microbiological aspects of aquatic ecosystem in the lake. The water quality variables (water temperature, $\mathrm{pH}, \mathrm{EC}$, total dissolved nitrogen and phosphate, SO2, BOD5 and microorganisms) were being measured seasonally during 2011.

The study concludes that high conductivity and sulphate concentrations were recorded during different seasons. Heterotrophic plate count and fecal coliform exceed the Iraqi and WHO standards for drinking purposes. Statistically, no differences were found between the studied sites for all variables. Microbiological isolates, counts

Mosher and Nawzet (2009), conducted a study that aimed to investigate environmental issues, pollution and its direct impact on human. This study pointed out to some properties Agayzaaiah, chemical and biological water and Mqaratnea with specifications and standards accredited.

The study results indicate that Mile $\mathrm{pH}$ values of the waters of the dam and water treatment toward the panel basal water was airy, either in terms of the overall top ten. Also, some elements such as calcium, magnesium and the values of electrical conductivity and total concentration of dissolved salts exceeded the permitted limit.

Naimi, et al. (2009), conducted a study that aimed to investigate some physical and chemical characteristics. The study concluded that the $(\mathrm{pH})$ concentration values are in the weak alkaline above the equivalent ratio of the $(\mathrm{pH})$ for all the stations during all the months of the year. The results also showed that the water samples contain salt ratio within the permitted ratios for drinking water in the most months of the year, New Baladruze station recorded the lower ratio (235) ppm compared with the two other stations, whereas the Old Baladruze station recorded the higher ratio in January (320) ppm. The electrical conductivity measures showed that it increases with increasing the quantity of total dissolved solids in the water. They found, the ratio of dissolved oxygen approximate values (8-12) ppm during the year.

MUSAWI, et al. (2009) conducted a study that aimed to investigate some Physical and chemical properties for drinking water in Babylon governorate. The study results indicate that the $\mathrm{pH}$ values tended to base ranged between Thilla. - were located on shatt (Al7.7). While, the $\mathrm{pH}$ values were varying of other pollutants during the months of the year but remain low for the spec sulfate that showed an increase over the limits of groundwater. With regard to the dissolved solids, international standard was compatible with the values of pollutants except total disso calcium, they showed an increase on the limit.

KAFIA et al. (2009), conducted a study that aimed to investigate the drinking water quality of Greater Zab river 
in Erbil, Kurdistan, Iraq, for human consumptions. Water samples were collected from three water treatment plants (WTP) on that river.

The study concludes that the efficiency of filtration unit of the three WTPs was: Efraz 1> Efraz 2> Efraz 3. Most of the parameters analyzed in this study were within the guidelines given by WHO or US EPA for drinking water while few others were not.

\section{The Practical Side}

The practical side includes analytical data for chemical and bacteriological tests from the private wells of AlDlail in a Zarqa from 8 / 6 / 2015 to 30 / 9 / 2015.

1. Total Dissolved Solid (T.D.S): Total dissolved solids (TDS) comprise inorganic salts (principally calcium, magnesium, potassium, sodium, bicarbonates, chlorides, and sulfates) and some small amounts of organic matter that are dissolved in water. In general, the total dissolved solids concentration is the sum of the cations (positively charged) and anions (negatively charged) ions in the water. Therefore, the total dissolved solids test provides a qualitative measure of the amount of dissolved ions but does not determine the nature or ion relationships. In addition, the test does not provide insight into the specific water quality issues, such as Elevated Hardness, Salty Taste, or Corrosiveness. Therefore, the total dissolved solids test is used as an indicator test to determine the general quality of the water. The sources of total dissolved solids can include all of the dissolved cations and anions, but the following table can be used as a generalization of the relationship of TDS to water quality problems (World Health Organization, Geneva, 1996).

2. Total Hardness (T.H): Total hardness is the hardness of the mineral content of water that is irreversible by boiling. Therefore, the total hardness can be equivalent to the total calcium and magnesium hardness. Total hardness is determined by the multivalent cations' concentrations present in water. These cations have a positive charge that is higher than $1+$. Typically, cations have a charge of $2+$. The most common cations present in hard water are $\mathrm{Mg} 2+$ and $\mathrm{Ca}+$. High hardness can result in abnormal cloudiness and formation of scale. However, levels of hardness that are too low could make the water corrosive and more aggressive. Thus, industries that utilize equipment and machinery that handles water should ensure that the total hardness levels are maintained at appropriate levels. This prevents the water from turning corrosive, causing damage not only to human health, but to industrial operations as well.

3. MPN/100mm: The most probable number (MPN) is the number of organisms that are most likely to have produced laboratory results in a particular test. The MPN method is used to quantify the concentration of the viable microorganisms in a sample and involves inoculating decimal dilutions into tubes of a broth medium, observing results and using a standard MPN table in order to get a more accurate number, more than one broth tube is inoculated from each dilution. Atypical test uses a minimum of three dilutions and three, five or ten tubes per dilution. The pattern of positive and negative tubes is then noted after the incubation and results checked against a standardized MPN table to determine the most probable number of microorganisms per unit volume of the original sample (World Health Organization, Geneva, 1996).

\section{Results and Discussion}

By using the statistical system through the application of quality maps, the chemical analysis of the data private and bacterial from private wells in Al-Dlail of a Zarqa Governorate, from 8 / 6 / 2015 to 30 / 9 / 2015 shown in Table (1).

Table 1. shows the results of laboratory for the Total Dissolved Solid (T.D.S), Total Hardness (T.H), Most Probable Number (MPN)

\begin{tabular}{llll}
\hline Date & T.D.S & T.H & MPN \\
\hline $8 / 6 / 2015$ & 571 & 248 & 1092 \\
$15 / 6 / 2015$ & 1029 & 484 & 3448 \\
$22 / 6 / 2015$ & 1088 & 488 & 241 \\
$29 / 6 / 2015$ & 445 & 192 & 688 \\
$5 / 7 / 2015$ & 573 & 280 & 1658 \\
$12 / 7 / 2015$ & 570 & 236 & 906 \\
$19 / 7 / 2015$ & 646 & 232 & 1421 \\
$26 / 7 / 2015$ & 670 & 232 & 1039 \\
$3 / 8 / 2015$ & 791 & 296 & 1019 \\
$10 / / 8 / 2015$ & 898 & 480 & 1112 \\
$17 / 8 / 2015$ & 1031 & 556 & 855 \\
\hline
\end{tabular}




\begin{tabular}{llll}
\hline $24 / 8 / 2015$ & 517 & 380 & 63 \\
$20 / 8 / 2015$ & 898 & 480 & 530 \\
$31 / 8 / 2015$ & 658 & 296 & 9804 \\
$3 / 7 / 2015$ & 517 & 380 & 6131 \\
$7 / 9 / 2015$ & 153 & 552 & 98 \\
$14 / 9 / 2015$ & 810 & 380 & 512 \\
$17 / 9 / 2015$ & 823 & 480 & 1354 \\
$21 / 9 / 2015$ & 1052 & 540 & 148 \\
$24 / 9 / 2015$ & 823 & 480 & 1515 \\
$28 / 9 / 1015$ & 194 & 144 & 134 \\
$30 / 9 / 2015$ & 100 & 484 & 1198 \\
\hline
\end{tabular}

First: Total Dissolved Solid(T.D.S)

By applying X-bar chart, the upper control limit of 1470, the lower control limit -38 and the ratio of T.D.S are within acceptable limits as shown in the figure (1).

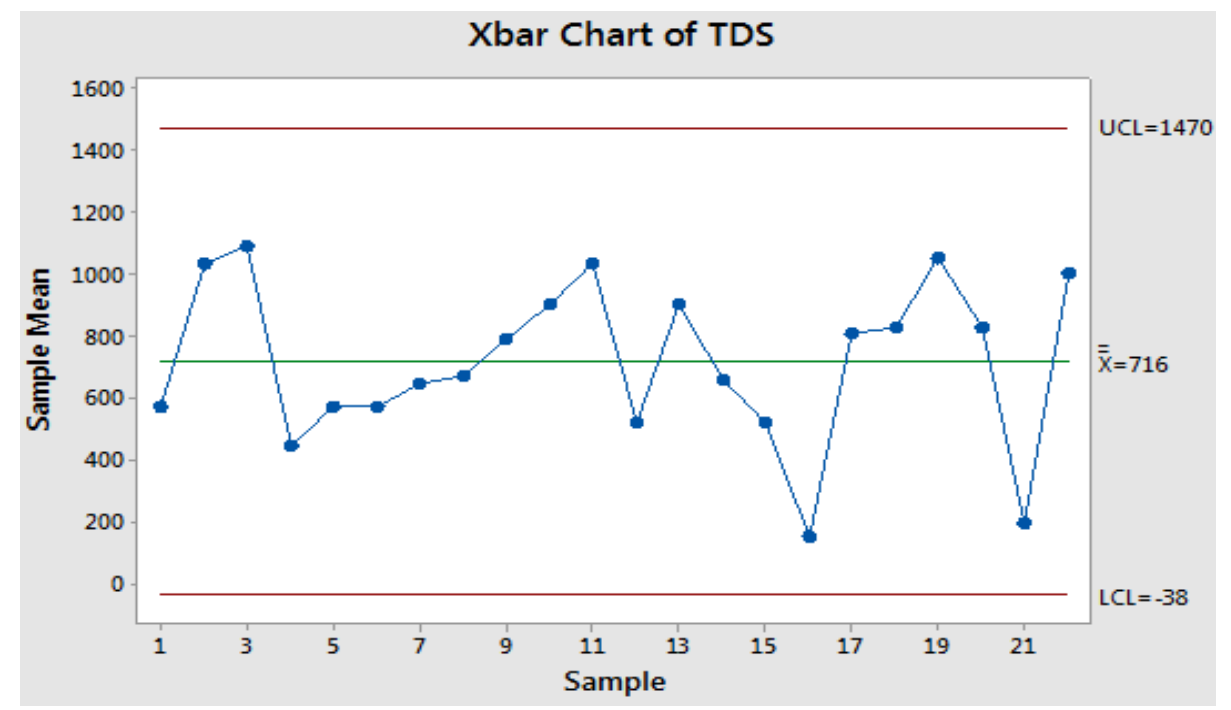

Figure 1. The control limits of the Total Dissolved Solid (T.D.S)

Figure (1) obviously express that the Upper Control Limit (UCL) was 1470 and the Lower Control Limit (LCL) was -38 , and the Central Limit was 716 . Five of the observations exceeded 1000 , which is $23 \%$ of the total observations. Two of the observations were less than 200, which is $9 \%$ of the total observations. But most of the observations aggregated around the central limit. Where four of the observations were close to the Central Limit (716), which is $18 \%$ of the total observations.

Generally, no observation exceeded the upper and the lower control limits, which means that all of them were within the acceptable limits.

\section{Second: Total Hardness (T.H)}

By applying X-bar chart, the upper control limit of 730.3, the lower control limit 26.1 and the ratio of T.H are within acceptable limits as shown in the figure (2). 


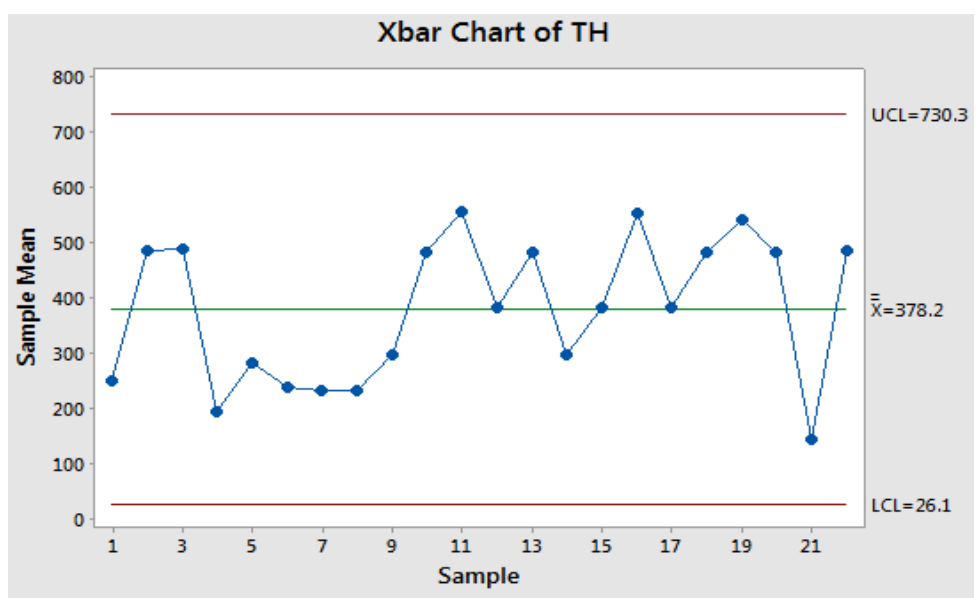

Figure 2. The control limits of the Total Hardness (T.H)

Figure (2) obviously expresses that the Upper Control Limit (UCL) was 730.3 and the Lower Control Limit (LCL) was 26.1, and the Central Limit was 378.2. Three of the observations exceeded 500, which is $13 \%$ of the total observations. Two of the observations were less than 200 , which is $9 \%$ of the total observations. But most of the observations did not aggregate around the central limit. Where three of the observations were identically equal to the Central Limit (378.2), which is $13 \%$ of the total observations. Generally, no observation exceeded the upper and the lower control limits, which means that all of them were within the acceptable limits. However, there were some extreme limits (observation number 21) but they were still within the normal limits.

Thirdly: MPN/100mm

By applying X-bar chart, the upper control limit of 6087, the lower control limit -2908 and the ratio of MPN. But some readings are beyond the extent of control. Also, there are two samples $(15,16)$ breaches the specification and the bacterium Bacillus colon (MPN), which means they exceeded the allowed percentage of the border and therefore require treatment of the water wells of the period in which the sample was taken. The results are shown in the figure (3).

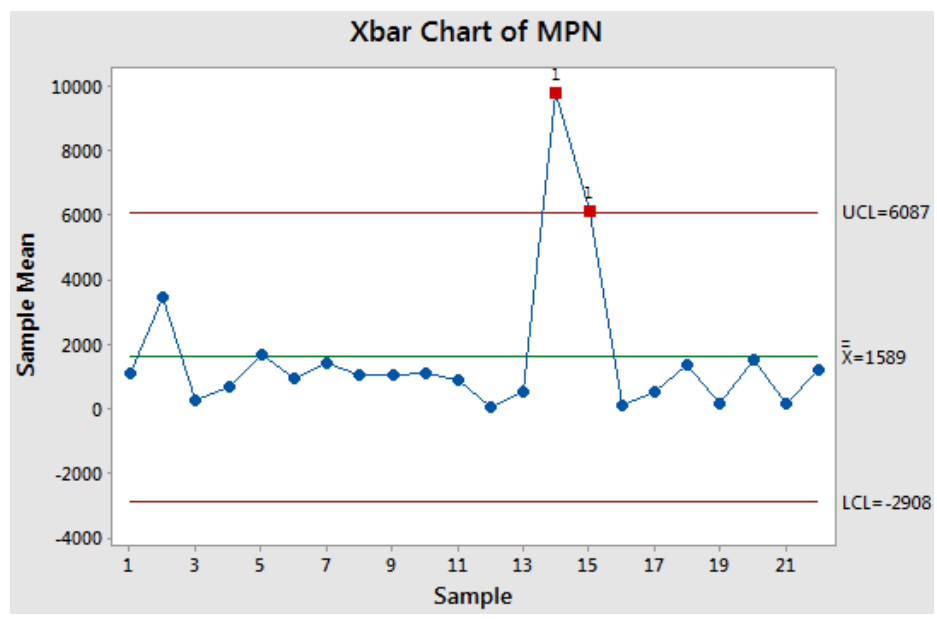

Figure 3. The control limits of the Most Probable Number (MPN)

Figure (3) obviously expresses that the Upper Control Limit (UCL) was 6087 and the Lower Control Limit (LCL) was -2908, and the Central Limit was 1589. Two of the observations exceeded the upper control limit (UCL=6087), which is $8 \%$ of the total observations. One of the observations was less than the upper control limit (UCL=6087) and above the central limit (MPN<4000), which is $4 \%$ of the total observations. But most of the observations aggregated less than the central limit. Where four of the observations was identically equal to the Central Limit was 1589 , which is $18 \%$ of the total observations. Generally, no observation exceeded the lower 
control limits, which means that all of them were not within the acceptable limits.

\section{Conclusion and Future Research}

Based on the results, the researcher concluded the following:

- The Control Limits for the Total Dissolved Solid(T.D.S) are within acceptable limits.

- The Control Limits for the Total Hardness (T.H) are within acceptable limits.

- The Control Limits for the Most Probable Number (MPN) are the around the central limits. But, there are two samples $(15,16)$ that breach the specifications and the bacterium Bacillus colon $(\mathrm{MPN})$, which means that they exceeded the allowed percentage of the border and therefore require treatment of the water wells up in the period in which the sample was taken.

\subsection{Future Research}

Future research should focus on the effective utilization of quality control in the other water management Jordanian stations. Future research should take this study into consideration to make further studies on water management station not only in Jordan ,but also in the surrounding groundwater basin that dose not within the Jordanian water management responsibility. This responsibility must be politically shared with the surrounding countries. Despite the fact that drinking water sources in Jordan are groundwater because of the lack of running rivers, and there were limited resources and technology for water management in Jordan, the results of the study mentioned that there were creative efforts done in the utilization of quality control. This case study that has been examined is an example of the effective utilization of quality control.

\section{The Contribution of the Study}

Adeeb Ahmed Ali ALRahamneh: Contributed to prepare, develop and carry out the analysis of the presented data, and carry out the statistical analysis for the amount of chemical properties and microbiology (T.D.S ,T.H,MPN) into water provided by the environmental health from the private wells Al-Dlail laboratories in a Zarqa Governorate.

\section{References}

Abdulraheem, A., Mustafa, S., Al-Saffar, N., \& Shahjahan, M. (2012). Detection of bacterial endotoxin in drinking tap and bottled water in Kuwait. Environ Monit Assess,184(12), 7323-8. https://doi.org/10.1007/s10661-011-2501-0. Epub 2012 Jan 21. Retraction in: Environ Monit Assess. 2013 Jul;185(7):6219. PubMed PMID:22270589.

Ahmad, M., \& Bajahlan, A. S. (2009). Quality comparison of tap water vs. bottled water in the industrial city of Yanbu (Saudi Arabia). Environ Monit Assess, 159(1-4):1-14. https://doi.org/10.1007/s10661-008-0608-8. Epub 2008 Nov 15. PubMed PMID:19011982.

Al-Kharabsheh, A., \& Alatoum, M. (2013). Effect of Agricultural Activities on Water Quality Deterioration of Mujib Basin, Jordan. Curr World Environ, 8(3). https://doi.org/10.12944/CWE.8.3.02

Amer, F. D. N. M. H. D., \& Wasfi, M. K. (2010). A study of some physical and chemical properties of drinking water in the district of Balad Ruz. Diyala Journal For Pure Sciences, 6(4).

Eman, M., Al-Musawi, Q. H., \& Ayoub, A. I. (2009). Study of Some Physical And Chemical Properties of Selected Plants For Drinking Water In Babylon Governorate. College of Engineering - University of Babylon.

Government laboratories/ Environmental Health of the private wells from Dlail in the city of Zarqa.

Guidelines for drinking-water quality (1996). 2nd ed. Vol. 2. Health criteria and other supporting information. World Health Organization, Geneva,

Jarugulla, E. S., \& Krishna, P. V. (2016). Assessment of Water quality in terms of physico - chemical parameters of East Godavari mangrove ecosystem (Coringa Wildlife Sanctuary) East Godavari, Andhra Pradesh, India.International Journal of Advanced Research, Int. J. Adv. Res. 5 (1), 782-788,ISSN: 2320-5407. https://doi.org/10.21474/IJAR01/2814 DOI URL: http://dx.doi.org/10.21474/IJAR01/2814.

Kafia, M. S., Slaiman, G., \& Muhamad, M. S. (2009). Physical and Chemical Status of Drinking Water from Water Treatment Plants on Greater Zab River, 13(3), 89-92.

Mosher, R. A., \& Nawzet, K. K. (2009). Assessment drinking water of Dohuk city. Journal of Dohuk Univ., 12(1), Kurdistan region, Iraq. 
Nancy, R. T. (2005). The Quality Toolbox, 2end. American Society for Quality. ISBN: 978-0-87389-639-9

Osama, R., \& Suleiman, A. (2008). Control charts for statistical quality and application on computers, $1^{\text {st }}$ edition. AL Manufia University.

Patil, P. N., Sawant, D. V., \& Deshmukh, R. N. (2012). Physico-chemical parameters for testing of water - A review. International Journal of Environmental Sciences, 3(3). ISSN 0976 - 4402.

Semerjian, L. A. (2011). Quality Assessment of Various Bottled Waters Marketed in Lebanon. Environ Monit Assess, 172, 275-285, / IVSL.

Taruna, J., \& Alankrita, C. (2013). Assessment of water quality and its effects on the health of residents of Jhunjhunu district, Rajasthan: A cross sectional study. Journal of Public Health and Epidemiology, 5(4), 186-191. https://doi.org/10.5897/JPHE12.096 ISSN 2006-9723 @2013 Academic Journals

Water Authority of Jordan Laboratories and Quality Sector Water Analysis (2013). Sampling and Historical Water Quality Data Price Lists. Retrieved from http://www.waj.gov.jo/sites/ar-jo/Documents/WAJ\%20Labs\%20Analysis\%20Brochure\%202013.pdf

Yahya, A. S., Hero, M. I., \& Akhter, A. A. (2013). Bacteriological and Mycological Assessment for Water Quality of Duhok Reservoir, Iraq. Jordan Journal of Biological Sciences, 6(4).

\section{Copyrights}

Copyright for this article is retained by the author(s), with first publication rights granted to the journal.

This is an open-access article distributed under the terms and conditions of the Creative Commons Attribution license (http://creativecommons.org/licenses/by/4.0/). 